\title{
Research on Water Restoration System in Wuhan City Based on Pocket Park Concept
}

\author{
Li Hongmin*, Fan Luping, and Zou Zuxu \\ School of Civil Engineering and Architecture, Wuhan Polytechnic University, Wuhan, China
}

\begin{abstract}
Wuhan city in Hubei Province is endowed with unique natural water resources and numerous lakes. It has a good framework of natural "green sponge", which provides a broad space for stormwater regulation and storage. However, with the increase of infrastructure construction in Wuhan, many lakes have been buried and the city is becoming a "hard shell city" made of steel and cement. This article combines the natural landform of Wuhan and the pocket park system theory to make an organic combination of the ongoing urban infrastructure construction and the restorative construction of the municipal water supply system in Wuhan, so as to make an exploratory research for the early construction of Wuhan into a sponge city.
\end{abstract}

\section{INTRODUCTION}

Along with the speeding up of urbanization, the city's impervious area gradually increases, the city is turning into concrete built in "city scale", the rain cannot get effective discharge or use. Meanwhile, water circulation system and ecological environment deteriorate even further.

In the three years from 2012 to 2015 , more than 360 cities in China experienced waterlogging. In order to improve the urban ecological environment, to eliminate urban waterlogging, the department of housing and urbanrural development issued a "sponge urban construction technology guide - low impact development of rainwater system build (trial)" in October 2014. In January 2015, the government launched a pilot program to construct sponge urban cities and there were 16 cities in it including Wuhan.

In foreign countries such as the United States, Japan, Australia and other countries in Europe, they studied the practices of urban water resource utilization management much early. They put forward "BMPs (Best Management Practices) water resources comprehensive management", "LID low impact development technology", "WSUD water sensitive urban design" concepts which obtained the very good applications in urban plannings and designs, and those can provide a good reference for our country.

Best Management Practices (BMPs) originated in the United States. The initial focus was on the reduction and control of non-point source pollution sources. In 1987, the United States published the Amendments to the Clean Water Act, and the acts stipulate the provisions of nonpoint source pollution control and incorporating the control requirements of stormwater runoff pollution into the national pollution discharge permit system. In 2003, BMP was expanded to include integrated stormwater management decision-making systems such as stormwater flood control, soil erosion control and reduction and control of non-point source pollution sources, with more emphasis on ecological design and non-engineering management measures that combine with natural ecology.

Low impact Development (LID) is a new concept of urban stormwater management developed on the basis of BMPs. LID emphasizes that in the case of rainfall, various rainwater control technologies such as storage, infiltration, evaporation, filtration, purification and retention should be used to restore the drainage state of rainwater after urban development close to the state before urban development.

In the late 1990s, water sensitive urban design (WSUD) is put forward in Australia, aimed at the problem of traditional drainage system and it put forward a rainwater management mode and method. The theory regards the urban water cycle as a whole, that is to say the tap water, sewage, drainage are all the components of the urban water cycle, and they should be considered comprehensive and thoroughly.

Since the 1990s, the concept of green infrastructure has been expanded in Europe and the United States. Although the meaning of green infrastructure construction is different in different countries and fields, in a broad sense, it all refers to the effective use of green space, wetland and rainwater storage and infiltration facilities. To be specific, in urban development and land use, it is devoted to the construction of rainwater storage and infiltration facilities, low-lying land, constructed wetland and other infrastructure by taking advantage of the functions of natural environment such as prevention of vegetation and water quality purification. 


\section{Sponge City and Pocket Park}

\subsection{Overview of Sponge City}

Sponge city means that cities, like sponges, have good resilience in adapting to environmental changes and responding to natural disasters brought by rain. The concept of sponge city is put forward under the concept of green and environmental protection. However, the sponge transformation of the residential area needs to combine the sponge technology with the terrain environment of the residential area, and in this process, there are many fields to explore and study. As one of the sponge city pilot cities, Wuhan also has the task of urban renovation, and some of the renovation problems faced by the residential areas are representative in the whole Yangtze River Basin and even the whole country.

The first goal of building a sponge city is to protect the original water ecosystem. Secondly, to restore the damaged water ecology is another purpose. For the urban green space, water body and wetland that have been damaged under the traditional extensive urban construction mode, the comprehensive application of physical, biological and ecological technology ways gradually restore the hydrologic cycle characteristics and ecological functions, maintain a certain proportion of urban ecological space, and promote the improvement of urban ecological diversity. Many places in China combine the point source wastewater treatment with the implementation of "river length system". It does great help in water pollution control, and it improves the water ecology as well. Third, low impact development. Fourth, various low-impact measures and system combinations are adopted to effectively reduce surface water runoff and reduce the impact of heavy rain on urban operation.

\subsection{Pocket park}

Under the guidance of the traditional "drainage oriented" stormwater management concept, most cities and towns quickly and directly discharge the collected rainwater into the receiving water body through the municipal rainwater pipe network, with little consideration given to infiltration into the soil, resource utilization and other ways of rainwater. The traditional municipal facilities are unable to cope with the sudden increase in rainfall during heavy rainfall or in the case of continuous rainfall for several days, which causes the city waterlogging problem.

However, the pocket park is another alternative in the system of sponge city. Figure 1 shows us the water drainage system of sponge city.

Pocket parks are characterized by flexible site selection, small area and discrete distribution. They can appear in large quantities in cities, which are like oases in the desert for cities crowded with tall buildings. They can change the urban environment to a large extent and partially meet the needs of people for parks in high-density urban centre.

The concept of pocket Park was first proposed at an exhibition organized by the New York Parks Association in 1963 as "a new Park for New York". Its prototype was to establish patches of Midtown Park, or pocket Park system, scattered in the high-density urban centre.

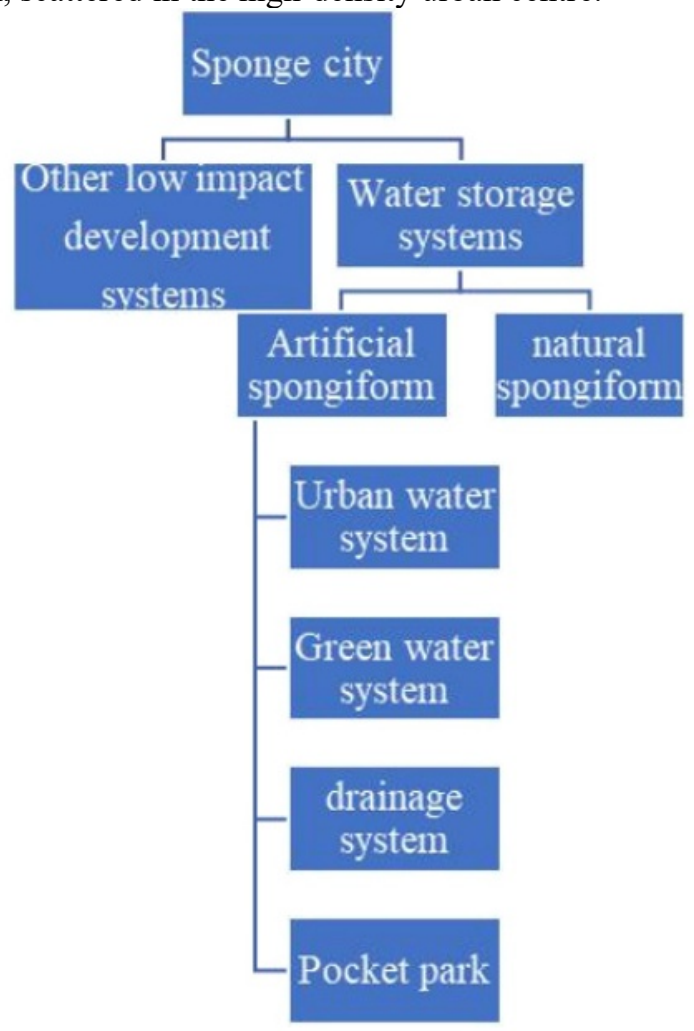

Fig1. . Water drainage system of sponge city

On May 23, 1967, Paley Park on 53rd Street in New York, the United States officially opened. This new form of urban public space came into being, marking the official birth of pocket Park. Peregrina Park responds well to Manhattan's conditions in terms of size and function, and it is as significant as Central Park.

\section{Based on the pocket park concept of the water system}

\subsection{Analysis of main causes of waterlogging}

\subsubsection{The hardened area of the underlying surface}

As can be seen from the rain drainage path diagram shown in Figure 2, a large number of hardened-pavement is adopted on the land, which results in the infiltration path of rain water being blocked, and the rain can only form runoff on the surface and then be drained away. This causes great pressure to the drainage of municipal pipes and drains. At the same time, many residential areas in Wuhan have the problem of poor construction of hardened-pavement, resulting in uneven roads, resulting in the destruction of the originally designed drainage slope, so that rain water is often concentrated in uneven potholes in rainy days.

\subsubsection{The green space is not set properly}

Green land is one of the underlying surface. Its surface runoff coefficient is not so high, but in the design, it is 
considered more about its landscape functions, usually set higher than the road after the saturated soil infiltration degrees. And that will be formed on the surface of green land runoff, go through the pipe line again. Nevertheless, soil in Wuhan is cohesive soil, the permeability of the soil is low, so, most of the rainfall can only pass through drainage discharge.

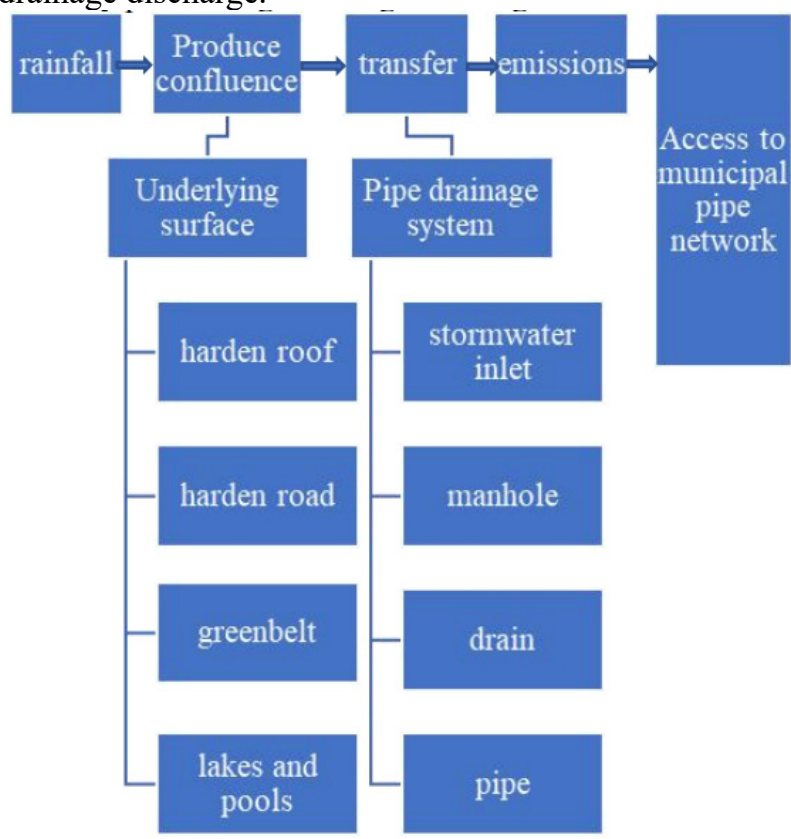

Fig2. rain drainage path

Another problem is the choose of vegetation. They were selected at will. Some plots chose vegetation that required a lot of water in the process of growth, resulting in excessive absorption of moisture in the soil by vegetation. Some communities chose some exotic vegetation, but as a result, the vegetation could not adapt to the climate of Wuhan or the protection situation was not ideal, and that lead to their death, which still could not play a good role in intercepting the runoff.

\subsubsection{The drainage capacity of the pipeline is insufficient}

After the formation of runoff, rainwater is gradually collected and flows into rainwater inlet and other water collection facilities, and then flows into the pipe and canal system for transfer. However, some rainwater outlets or other water collection facilities in some communities become inefficient due to poor maintenance. At the same time, the drainage pipe and canal are not enough. The drainage pipe diameter of many early-built communities in Wuhan is only $300 \mathrm{~mm}$, and the designed flow capacity can only meet the basic drainage. However, as long as there is heavy rainfall, it will be overloaded, resulting in the failure of timely and effective discharge of rainfall, resulting in water accumulation in the community.

\subsection{Analysis of current situation of rainwater and flood control in residential areas in Wuhan}

The total water area of Wuhan is 2,217.6 square kilometres, with a coverage rate of $26.10 \%$. There are 166 lakes in
Wuhan, covering a total area of 867 square kilometres, accounting for $10.2 \%$ of the total land area of Wuhan. The wetland covers an area of 3,195.85 square kilometres. Wuhan is a large city in China with abundant fresh water resources, so it provides a strong foundation for the construction of Wuhan sponge city. Affected by the quasistationary front of the Yangtze River and Huai River. Wuhan is very representative among the cities in the Yangtze River basin. Wuhan is located at the northern edge of the subtropical humid monsoon climate zone, with abundant rainfall. The average annual rainfall is $1304.3 \mathrm{~mm}$, the maximum annual rainfall is $2105.9 \mathrm{~mm}$, and the average annual evaporation is $949.8 \mathrm{~mm}$. Heavy rain is mostly concentrated in May to August every year, with the maximum daily rainfall of $473 \mathrm{~mm}$ and maximum hourly rainfall of $120 \mathrm{~mm}$. The occurrence frequency of summer and autumn rainstorm is relatively high, especially mesoscale rainstorm, which usually has the characteristics of small range, large intensity, short duration and strong suddenness, etc.. And that can easily lead to the formation of waterlogging in the residential area of Wuhan in a short time. It is a typical rainy city in the south.

However, at present, most of the rainwater control methods in existing communities in Wuhan are based on traditional drainage facilities, such as wells, pipes and channels. The rainwater runoff process can be divided into three stages: generating confluence, transferring and discharging. The confluence stage refers to the process in which the rainwater gradually converges to form runoff after a series of process such as depression, infiltration and evaporation on the underlying surface of the site after the occurrence of rainfall, and finally drains to the stormwater inlet and other water collection facilities. The transfer stage is the process in which stormwater runoff is collected in the pipeline and transferred to the outlet. The discharge stage is the way to treat rainwater in the final stage of rainwater. The usual way to dispose of rainwater in the community is to drain it into the municipal pipeline network.

\subsection{Pocket Park Solution}

The "pocket park" covers an area of $300 \sim 5,000$ square meters, and many of them are built by using the "spare parts" in the urban construction land. The site selection is flexible and the construction period is short, so they have advantages in creating the personality and characteristics of the park. The Table 1 shown below is an overview forms of pocket parks.

Through the investigation of urban street corner green space in the old city, it is found that most street corners in the city are mainly hardened with a large area of the ground, lacking the necessary green shady areas and leisure places. The large area of hardened ground intensifies the reflection of light and heat, and does not have the function of dustproof and noise reduction, so people are not willing to go to this kind of space for leisure and activities, causing a waste of social public resources. Therefore, a new form of "pocket park" should be created to meet the needs in Wuhan style. 
Table1. Overview of pocket parks

\begin{tabular}{|c|c|c|c|}
\hline & type & $\begin{array}{c}\text { Scale } \\
/ \mathrm{m}^{2}\end{array}$ & Construction forms \\
\hline 1 & $\begin{array}{c}\text { Small open Spaces } \\
\text { in non-urban green } \\
\text { Spaces }\end{array}$ & $\begin{array}{c}\geq 0 \sim 400 \\
\text { Shrubs+ stools }\end{array}$ & $\begin{array}{c}\text { Shrubs+ stools+ entourage } \\
\text { tree array }\end{array}$ \\
\hline 2 & greenbelt & $\begin{array}{c}10 \sim 100 \\
\geq 100\end{array}$ & $\begin{array}{c}\text { Shrubs+ stools } \\
\text { Green space+ public facilities }\end{array}$ \\
\hline 3 & $\begin{array}{c}10 \sim 400 \\
\text { Street green space }\end{array}$ & $\begin{array}{c}\text { Sall green space+ public } \\
\text { facilities; } \\
\text { public facilities+ entourage } \\
\text { green space+ sport space+ public } \\
\text { facilities }\end{array}$ \\
\hline 4 & $\begin{array}{c}\text { Green space for } \\
\text { public facilities }\end{array}$ & $\begin{array}{c}\geq 400 \\
\geq 400\end{array}$ & $\begin{array}{c}\text { Small green space+ stools } \\
\text { Green space+ sport space }\end{array}$ \\
\hline 5 & $\begin{array}{c}\text { Residential green } \\
\text { space }\end{array}$ & $\geq 100$ & Green space+ public facilities \\
\hline 6 & Community park & $\geq 4000$ & Green space+ sport space+ public \\
facilities
\end{tabular}

Pocket park is mainly a public space with small scale, close to people's life and flexible use function, which is made of unbuilt urban green space, idle land and urban micro-space. For example, in the event of a major natural disaster, it can be used to set up temporary relief tents and distribute relief supplies.

It is reported that an average of about 40 "street parks" have been built in Wuhan every year since 2017. And a green highlight is the construction of 100 "pocket parks" in Wuhan in 2020 greening plan.

\subsection{The Pocket Park application case}

Lingang district Home Service Station and Green Leisure Square is a typical pilot project, it have been transformed into a "pocket park" with amazing feedback. This is one of the projects of Lingang district in Shanghai to promote sponge city construction.

Before transformation, rainfall was often accumulated in the area on rainy days. And that causes a lot of problems.

In view of the problems existing in the original, and combining with problems such as parking, recreation, sports and other requirements, the designer chose "permeable pavement + flat drain + rain garden" technology combination. The permeable brick can let the rain infiltration, excessive amounts of rainwater drainage collected through the cover board in the rainwater garden. In addition, "green roof" not only realizes the roof rainwater runoff absorption, but also solves the perennial water leakage problem; "Ecological parking space" has green plants and it is permeable, which can also solve the parking problem of residents. The construction of "permeable circular track" provides residents with fitness trails.

The improved "pocket park" also upgraded its waterlogging capacity. It is reported that the green area of Lingang Home service station and green leisure square has reached 1.3 hectares, accounting for $66 \%$ of the total area. The pocket park is able to absorb 158 cubic meters of rainwater runoff in the local block and has a surplus capacity of 190 cubic meters.

\section{Conclusion and prospect}

The green work plan for 2020 in Wuhan was released on May 26. and it declared that the city will build 700 hectares of new urban green space by combining the establishment of a national ecological garden city and an international wetland city with the revitalization after the epidemic. In addition, 100 pocket parks will be built.

Wuhan city will start the construction of "5-minute Service Circle of urban Park green space" for two years, and plans to carry out the construction of urban park and "pocket park" for two consecutive years, so that the service radius of urban park green space covers more than $90 \%$ of the residential land, and citizens are expected to enter the park green space within 5 minutes walking out of their homes.

The construction of pocket park can not only improve the life of residents, but also change the urban waterlogging situation. Pocket park is an important part of sponge city construction.

\section{References}

1. Liu H.M., Sun W.J., Shen S.L., et al. Flood risk assessment in metro systems of mega-cities using a GIS-based modeling approach. Science of The Total Environment, 626, 1012-1025 (2018)

2. Technical guide for sponge city construction (Trial), Ministry of housing and urban-rural development (2014)

3. Li J., Deng C., Li Y., et al. Comprehensive Benefit Evaluation System for Low-Impact Development of Urban Stormwater Management Measure. Water Resources Management, 31(14), 1-14(2017)

4. Park J., Kim J. H, Dong K L., et al. The influence of small green space type and structure at the street level on urban heat island mitigation. Urban Forestry \& Urban Greening, 21, 203-212 (2016)

5. Li J, Deng C, Li H, et al. Hydrological Environmental Responses of LID and Approach for Rainfall Pattern Selection in Precipitation Data- Lacked Region. Water Resources Management, 32, 4(2018)

6. Wu Lianfeng, A case study of the sponge city construction plan in built-up areas, Water\& Wastewater engineering, 45, 11(2019)

7. Jennifer R. Wolch, Jason Byrne, Joshua P. Newell. Urban green space, public health, and environmental justice: The challenge of making cities 'just green enough'. Landscape and Urban Planning, 125, 234244 (2014) 